\title{
Entrevista com Samuel Pfromm Netto
}

Samuel Pfromm Netto tem 67 anos de idade. Nasceu em Piracicaba a 3 de março de 1932, em uma família com ascendentes maternos luso-brasileiros católicos e paternos luteranos alemães. Formou-se pela USP em Pedagogia (1959) e tem mestrado e doutorado em Psicologia pela mesma universidade. Fez estudos de pós-doutorado nos EUA, na Inglaterra, na França, na Alemanha e no Japão. Chefiou missões culturais a este último país e à China, tendo proferido conferência em ambos. Sua produção bibliográfica compreende mais de quarenta livros, como Telas que ensinam (1998), Psicologia: introdução e guia de estudo (1990, 23 ed.), Psicologia da aprendizagem e do ensino (1987), Tecnologia da educação e comunicação de massa (1977),Comunicação de massa (1972), Psicologia da adolescência (sete edições) e mais de uma centena de estudos e pesquisas publicados em revistas especializadas do país e do exterior. Atuou em várias entidades culturais e ligadas à Psicologia, lecionou por muitos anos na USP e presentemente professor titular da PUCCampinas, nos cursos de doutorado mestrado (Psicologia Escolar). Preside a Academia Cristã de Letras, é vice-presidente do Instituto Histórico e Geográfico de São Paulo e atua como coordenador geral do programa de educação à distância do CIANET em São Paulo. É casado e tem uma filha e um neto. Seus gostos e preferências incluem a música barroca, a música tradicional brasileira, a literatura de ficção, os clássicos do cinema, bons vinhos e uísques e o Corinthians Paulista. Recebeu duas dezenas de medalhas e diplomas honoríficos do país e do exterior.

\section{Entrevistadora: Geraldina Porto Witter}

\section{Witter - Que variáveis o levaram a optar pela Psicologia como área de atuação?}

Pfromm Netto - Leciono há meio século. Comecei a dar aulas e publiquei meu primeiro trabalho de pesquisa, sobre crianças e cinema, em 1949.

Sou de um tempo em que não havia no Brasil a formação de psicólogos em cursos superiores de graduação. Antes da Lei 4119 de 1962, essa formação se dava somente em cursos pós-graduados como o de especialização, oferecido na USP pela antiga cadeira de Psicologia Educacional, curso com vários anos de duração que foi depois equiparado ao mestrado. Até a década de 60, os psicólogos geralmente se formavam em Pedagogia ou em Filosofia na graduação e prosseguiam seus estudos nos cursos de especialização dados pela USP, PUC e outras Universidades. É bom lembrar que, no caso da Psicologia Educacional, havia uma sólida tradição de ensino, prática e pesquisa em institutos de educação e nas escolas normais de todo o país que, nas primeiras décadas do século, prepararam a maioria das pessoas que passaram a fazer, investigar e ensinar psicologia. Foram pioneiros como Lourenço Filho, Souza Ferraz, Noemy Rudolfer e muitos outros. Foi nesse contexto, como estudante norma lista, que eu conheci a Psicologia e apaixonei-me por ela, uma paixão que já dura mais de meia centena de anos, pois eu me formei como professor primário na Escola Normal de Piracicaba em 1949. Por ocasião dessa experiência como estudante normalista, dois professores me serviram de incentivo e ajuda, sendo em boa parte responsáveis pela paixão a que me referi: José Rodrigues de Arruda, pioneiro nos estudos sobre aprendizagem de idiomas estrangeiros e em testes de inteligência e escolares, autor de um notável compêndio de Psicologia editado pela Saraiva, e Antonio Martins Belmudes de Toledo. Freqüentava as casas de um e outro, ganhei livros de Psicologia de ambos (inclusive uma volumosa obra de Pavlov) e lhes devo boa parte do meu entusiasmo de ontem e de hoje pela Psicologia. Eles despertaram em mim o gosto pelo 
estudo e pela aplicação da Psicologia no contexto escolar.

\section{Witter - Poderia descrever sua formação profissional?}

Pfromm Netto - A minha formação, iniciada como disse, nos tempos do curso normal de saudosa memória, prosseguiu com uma mescla de cursos de férias, autodidatismo e muita, muita leitura. Graças a isso, fui aprovado em três concursos públicos para lecionar Psicologia, Pedagogia, Didática e História e Filosofia da Educação no ensino normal paulista, na década de 50. Lecionei Psicologia em Piracicaba, Paraguaçu Paulista, Santa Cruz do Rio Pardo, Tatuí, na capital paulista... Já casado e pai de uma filha pequena, acabei ingressando na Faculdade de Filosofia da USP, na rua Maria Antonia. Foi o tempo em que privei com alguns dos maiores nomes da Psicologia de então, como Rudolfer, Angelini, Odette Van Kolck, Osvaldo de Barros Santos, Joel Martins, Dante Moreira Leite, Anita Cabral e conheci figuras ilustres como Lourenço Filho, Fernando de Azevedo, Antonio Teixeira, Laerte Ramos de Carvalho e tantos outros. Orgulho-me de ter sido aluno de vários daqueles que iniciaram a Psicologia Científica de pesquisa, de laboratório, dos testes e medidas, a serviço da educação aqui em São Paulo. Terminada a graduação em Pedagogia, recebi um convite de Angelini para trabalhar na antiga cadeira de Psicologia Educacional. Assim, estreei na USP como professor no ano seguinte (1960) ao da minha formatura, como encarregado da parte prática (pesquisas e experiências em laboratório) da disciplina Psicologia da Aprendizagem, cuja parte teórica era ministrada pelo próprio Angelini. Nessa condição, participei ativamente das numerosas reuniões que resultaram na criação do Curso de Psicologia da USP, das batalhas graças às quais saiu a "Lei do Psicólogo" em 62, assim como efervescência em tomo da criação dos Conselhos de Psicologia. Fui, aliás, conselheiro por muitos anos do nosso CRP, que tive a honra de presidir, e pertenci à diretoria da combativa Sociedade de Psicologia de São Paulo.

Conclui meu doutorado na própria USP e fiz estudos pós-graduados no exterior (nos EUA, Europa e Japão), que me foram preciosos para a reformulação das minhas concepções, práticas e atuações como professor pesquisador, pesquisador e profissional ativo em várias áreas - a escolar, a clínica, a do trabalho, a da mídia, principalmente em TV e rádio. Devo, aliás, à mídia, outra paixão antiga, grande parte do que sei e faço até hoje, pois fui jornalista e radialista quando moço, fiz cinema, fiz televisão (na TV Cultura, entre 72 e 75) e na Funtevê, no Rio de Janeiro.

Acabei me metendo na informática educativa, nos anos 70 e 80. Colaborei com a Secretaria Especial de Informática do Governo Federal no planejamento e na criação dos primeiros centros de informática educativa no país. E com o MEC, nos júris de premiação dos melhores "softwares" educativos feitos no Brasil. Lembro-me com orgulho de ter participado da primeira experiência de ensino-aprendizagem à distância por meio de computador, que uniu São Paulo ao Rio de Janeiro por meio de linha telefônica, em 1971. Conto essa história no meu livro Telas que Ensinam. Foi o começo, que levou à aprendizagem via computador, Internet, CD-roms, realidade virtual e outros desenvolvimentos recentes. A participação dos psicólogos na mídia a serviço de ensino e aprendi agem e a sua preocupação com os efeitos da mídia nas pessoas, aliás, é antiga entre nós, desde os tempos de Lourrenço Filho, que nos anos 20 já fazia pesquisa sobre os efeitos do "cinematógrafo" nas crianças. Entre as quatro dezenas de livros que escrevi e publiquei, vários deles se referem à mídia educativa e a relacionam com a Psicologia.

\section{Witter - Dentre as muitas áreas da Psicologia por que escolheu a área Educacional?}


Pfromm Netto - Como já disse, fui professor normalista e lecionei nos cursos normal e colegial (ensino secundário), antes de trabalhar no ensino superior. Desde os tempos de estudante normalista, eu me interessei pela aplicação da Psicologia ao ensino-aprendizagem, pelo desenvolvimento psicológico da criança e do adolescente, pelos fundamentos psicológicos da mídia a serviço da educação, pelas dificuldades de aprendizagem. Era, pois, natural que me inclinasse mais pela área de Psicologia Educacional, o que não me impediu de trabalhar como psicólogo clínico por algum tempo (tive consultório durante vários anos à rua D. Veridiana em São Paulo, à frente da Santa Casa) e de, até hoje, me dedicar à área de treinamento e desenvolvimento de recursos humanos, ou mais genericamente, à chamada "Psicologia do Pessoal".

Witter - Às vezes, olhando o passado as pessoas gostariam de ter feito outras opções, dado outros encaminhamentos ao seu percurso no mundo do trabalho. Se você pudesse refazer algo em sua trajetória, escolheria outra profissão ou outra área da Psicologia? Por quê?

Pfromm Netto - Com franqueza, se eu tivesse que nascer de novo, não mudaria absolutamente nada na minha vida, particularmente no que respeita à opção profissional. Mudaria somente as datas: gostaria de começar a partir do ano 2000, que marcará o início de uma fase maravilhosa na história da humanidade e, tenho certeza, na história da Psicologia. Já pensou quanta, quanta coisa boa vai acontecer nas próximas décadas? Felizes os psicólogos que estarão em plena atividade de 2000 a 2050 !

Witter - Desde o surgimento da ABRAPEE você se faz presente e tem colaborado muito para seu desenvolvimento. Poderia contar um pouco de seu relacionamento com a ABRAPEE?

Pfromm Netto - A ABRAPEE é fruto do idealismo, do entusiasmo e da dedicação de um grupo de excelentes amigos e colegas. Muito mais a eles do que a mim se deve a concretização desse sonho, de modo que a parcela que me cabe - se é que me cabe alguma - na história da ABRAPEE é bastante modesta. Na concepção inicial, a ABRAPEE-SP, era na verdade, o núcleo pioneiro e fundamental, e foi mais à frente desse núcleo, hoje absorvido pela ABRAPEE-Nacional, que dei a minha principal colaboração. Ajudei, além disso, na criação da Associação, na realização dos nossos primeiros congressos e atividades etc. A história da ABRAPEE é uma história coletiva, da dedicação de um punhado de pessoas, e não vejo muito sentido em me deter a respeito do meu relacionamento com nossa entidade, que está em excelentes mãos e precisa da colaboração de todos nós, indistintamente.

Witter - O que considera como características marcantes da Psicologia Escolar no Brasil de hoje?

Pfromm Netto - Vejo aspectos positivos e negativos, na Psicologia Escolar brasileira dos nossos dias. Primeiro os positivos. Graças principalmente à ABRAPEE, aos congressos promovidos por esta e a outros empenhos e realizações, em que destaco a comunidade das publicações como a Revista, os Anais, os Boletins, temos hoje uma produção e uma publicação de pesquisas das mais expressivas, em comparação com o que tínhamos nas décadas passadas. Boa parte dessa produção obedece aos melhores padrões da literatura internacional e se debruça, para nossa satisfação, sobre a realidade de professores e alunos brasileiros em escolas brasileiras. Noto, também, um aumento expressivo de contribuições, muito raras no passado, da pesquisa empírica sobre distúrbios e 
problemas de aprendizagem com embasamento científico sério, ao contrário de uma certa linha de superficialidade, pixação e desconhecimento brutal do complexo de fatores, condições e componentes não só psicológicos e sociais, como bioquímicos, genéticos, neurais e traumáticos e de relacionamento interpessoal, que nos fornecem um quadro de referência muito mais seguro para fins de prevenção, intervenção e atuação junto a escolares, pais e professores. Temos hoje muito mais consciência do alerta feito por Bronfenbrenner (desde a década de 70), Postman (principalmente em The disapearance of childhood), Rutter, Eron e outros, sobre a progressiva deterioração, na sociedade, das condições indicadas pelas pesquisas como críticas tanto para um desenvolvimento saudável na infância como para a manutenção da saúde física e mental e das competências humanas ao longo da vida. Por outro lado, a riqueza da literatura científica atual em Psicologia Escolar e em áreas associadas (desenvolvimento, aprendizagem, personalidade, cognição, avaliação psicológica, excepcionais e educação especial) deixa claro que já é tempo de abandonar a "adoração" deste ou daquele paradigma, deste ou daquele nome ilustre, e adotar uma visão múltipla, flexível, ao mesmo tempo eclética e integradora, em Psicologia Escolar.

Em contrapartida, há os aspectos negativos. Apesar dos múltiplos esforços no sentido de pôr um psicólogo escolar em cada escola, infelizmente, o recente veto presidencial frustrou as nossas expectativas nesse sentido. Ressentimo-nos ainda de uma certa timidez, de um certo pudor despropositado quanto à necessidade de fazermos o nosso próprio marketing, de organizar lobbies, de mobilizar pessoas e sociedades para dotar nossas escolas de bons serviços e profissionais competentes no âmbito da Psicologia Escolar. Por falar em profissionais competentes, é bem sabido que deixa a desejar, em numerosos cursos, a preparação desses profissionais, que é mínima ou nula, ou que se desloca do aprendizado de conhecimentos e habilidades (sem dúvida mais trabalhoso) para o caminho fácil da contestação barata, das arengas político-doutrinárias e da maledicência mal disfarçada que perdem de vista a própria psicologia. Um triste reflexo desse estado de coisas se encontra nos livros que os nossos estudantes estão lendo: são antigos, defasados ou, pior ainda, são meros discursos polêmicos que em nada contribuem para o desenvolvimento das competências essenciais que o psicólogo escolar deve ter ou para pô-lo ao corrente do "estado da arte" no que respeita à teorização, à pesquisa e à prática da Psicóloga Escolar no mundo inteiro, já que não podemos esquecer a nossa condição de pesquisadores e profissionais num âmbito internacional. Este é, creio, um dos nossos principais desafios: traduzir (e convencer os editores a publicar) bons textos contemporâneos de autêntica Psicologia Escolar e produzir textos originais, destinados aos estudantes e aos profissionais da nossa área. Estes e outros pontos negativos convergem para um desafio sério: precisamos trabalhar melhor o senso de identidade profissional do Psicólogo Escolar. Conhecer mais o nosso passado que, como tenho acentuado em vários trabalhos (e que espero reunir em tema de livro no ano 2000, História da Psicologia Escolar e Educacional no Brasil), mergulha suas raízes em tempos bastantes remotos. Definir mais claramente as habilidades e os conhecimentos que devem obrigatoriamente compor o perfil do psicólogo escolar. Promover mais a nossa área, o nosso potencial, os benefícios que resultam para os escolares e a sociedade em geral, graças à intervenção e à prevenção o mais cedo possível na vida da criança, junto aos professores, aos pais, aos que participam dos cuidados à infância e à adolescência brasileiras. Fazer com que os psicólogos escolares se tornem mais reconhecidos, mais requisitados e mais envolvidos no dia-a-dia das escolas de todos os tipos. Aperfeiçoar e atualizar continuamente esses profissionais.

\section{Witter - Como vê o futuro da Psicologia Escolar?}


Pfromm Netto - "O futuro a Deus pertence", eis uma frase feita que parece justificar a falta de iniciativa, a omissão, a indiferença, as críticas a uma visão e atuação proativas. Insurjo-me contra esse fatalismo, esse cruzar os braço, essa despretensão. Cabe-nos a nós mesmos a construção do futuro da Psicologia Escolar. Ela serão que fizermos hoje, ou desgraçadamente, o que deixamos de fazer. W. Kessen, em livro publicado em 1990 (The rise andfall ofdevelopment. Worcester,Clark Up), concluiu que, "independentemente do estilo de raciocínio que adotarmos, as provas científicas acumuladas nas últimas décadas, a partir de culturas e grupos diferentes de pessoas, se opõem fortemente a Grandes Simplicidades Teóricas ou Metodológicas" (pág. 29). Isto vale para o futuro da Psicologia Escolar no Brasil e no mundo. Precisamos ampliar sensivelmente a nossa base de conhecimentos, fugir de certas formulações simplistas ou anacrônicas, recusar a sedução da busca de bodes expiatórios para problemas individuais ou sociais, abandonar o hábito de recorrer unilateralmente a este ou aquele paradigma, a esta ou aquela teoria pretensiosamente capaz de tudo explicar, de tudo abranger. O psicólogo escolar autêntico não é um adorador de ídolos, mas um profissional que sabe pensar, avaliar, resolver problemas, tomar decisões inteligentes - no melhor interesse de cada escolar que é objeto da sua atenção.

Witter - Samuel, como sempre, foi um prazer poder contar com você nesta entrevista. Mais ainda, foi uma oportunidade para aprender sobre a Psicologia, a profissão, mas principalmente sobre atitudes e valores científicos de alguém que sempre esteve e está adiantado em relação ao seu tempo. De há muito você já passou o ano 2000, daí o seu otimismo. Muito obrigada. 